University of South Carolina

Scholar Commons

2-19-2009

\title{
Unveiling the Formation Mechanism of Pseudo-Single-Crystal Aragonite Platelets in Nacre
}

\author{
Xiaodong Li \\ University of South Carolina - Columbia, lixiao@cec.sc.edu \\ Zaiwang Huang
}

Follow this and additional works at: https://scholarcommons.sc.edu/emec_facpub

Part of the Mechanical Engineering Commons

\section{Publication Info}

Published in Physical Review Letters, Volume 102, Issue 7, 2009, pages 075502-.

(c) Physical Review Letters 2009, The American Physical Society.

$\mathrm{Li}, \mathrm{X}$. \& Huang, Z. (2009). Unveiling the Formation Mechanism of Pseudo-Single-Crystal Aragonite

Platelets in Nacre. Physical Review Letters, 102 (7), 075502. http://dx.doi.org/10.1103/

PhysRevLett.102.075502

This Article is brought to you by the Mechanical Engineering, Department of at Scholar Commons. It has been accepted for inclusion in Faculty Publications by an authorized administrator of Scholar Commons. For more information, please contact digres@mailbox.sc.edu. 


\title{
Unveiling the Formation Mechanism of Pseudo-Single-Crystal Aragonite Platelets in Nacre
}

\author{
Xiaodong $\mathrm{Li}^{*}$ and Zaiwang Huang \\ Department of Mechanical Engineering, University of South Carolina, 300 Main Street, Columbia, South Carolina 29208, USA
}

(Received 8 December 2008; published 19 February 2009)

\begin{abstract}
We demonstrate direct evidence that a single-crystal-like aragonite platelet is essentially assembled with aragonite nanoparticles. The aragonite nanoparticles are readily oriented and assembled into pseudosingle-crystal aragonite platelets via screw dislocation and amorphous aggregation, which are two dominant mediating mechanisms between nanoparticles during biomineralization. These findings will advance our understanding of nacre's biomineralization process and provide additional design guidelines for developing biomimetic materials.
\end{abstract}

DOI: 10.1103/PhysRevLett.102.075502

PACS numbers: 62.20.F-, 46.50.+a, 81.07.-b, 87.85.J-

Seashells have long been identified as natural armor materials with superior mechanical strength and toughness. The structure of seashells has evolved through millions of years to a level of optimization not currently achieved in engineered materials [1]. One of the best examples is nacre (mother of pearl) that is found in the shiny interior of many mollusk shells. Nacre is composed of approximately 95 vol.\% brittle inorganic aragonite (a mineral form of $\mathrm{CaCO}_{3}$ ) and a small percentage of organic biopolymer [2]. This material has a brick-and-mortar-like structure with highly organized polygonal aragonite platelets of a thickness ranging from 200 to $500 \mathrm{~nm}$ and an edge length of about $5 \mu \mathrm{m}$ sandwiched with a 5-20 nm thick organic biopolymer interlayer, which assembles the aragonite platelets together [3]. Previous transmission electron microscopy (TEM) studies showed that the electron diffraction patterns of individual aragonite platelets have characteristics of single-crystal electron diffraction [4-6]. It has long been thought that aragonite platelets are brittle single crystals. However, recent atomic force microscopy (AFM) observation $[3,7,8]$ revealed that individual aragonite platelets in fact consist of a large number of nanometer-sized particles with an average size of $32-44 \mathrm{~nm}$ and the aragonite platelets are not brittle but ductile. This distinctly contradicts the fact that individual aragonite platelets scatter as single crystals in TEM diffraction. A key question is raised, but not answered: how do nacre's aragonite platelets exhibit a dual nature with the characteristics of both monocrystal and polycrystals (nanoparticles) in such a contradictory manner? Here we report new mechanisms that nature uses to fabricate nacre's aragonite platelets at the nanoscale.

In this Letter, natural nacre materials from California red abalone (Haliotis rufescens) that belong to the class of gastropoda were studied. The shells were collected alive in Santa Barbara, CA. To minimize the detrimental effect of drying on the structure of shells, they were cleaned and air delivered in ice to the laboratory where the experiments were conducted. Nacre samples were cut from the nacre layer of the shells with a water-cooled, low-speed diamond saw. Then the nacre samples were rinsed thoroughly with distilled water. The TEM samples were prepared by sectioning the nacre using the microtome technique (Microm HM 325 Rotary Paraffin Microtome) and then transferred onto the holey carbon-coated copper film for observation in a JEOL JEM $2100 \mathrm{~F}$ transmission electron microscope with an accelerating voltage of $200 \mathrm{kV}$.

Nacre's cross section resembles a brick wall with aragonite platelets with [001] orientation toward organic biopolymer interlayers, as shown in Fig. 1(a). The electron diffraction patterns of individual aragonite platelets exhibit characteristics of a single crystal [Fig. 1(b)]. The high resolution TEM (HRTEM) image [Fig. 2(a)] reveals that individual aragonite platelets consist of a large number of nanoparticles. This is in good agreement with the recent AFM observation [3,7,8]. Fast Fourier transformation (FFT) analysis reveals that these nanoparticles are aragonite [see inset in Fig. 2(a)]. Some nanoparticles in the platelet hold the same crystal orientation. Here, let us take two particles in the boxed area in Fig. 2(a) as an example. Lattice fringe details [Fig. 2(b)] suggest that the interface between the two adjacent nanoparticles involves a slip of one particle relative to the other along [010]
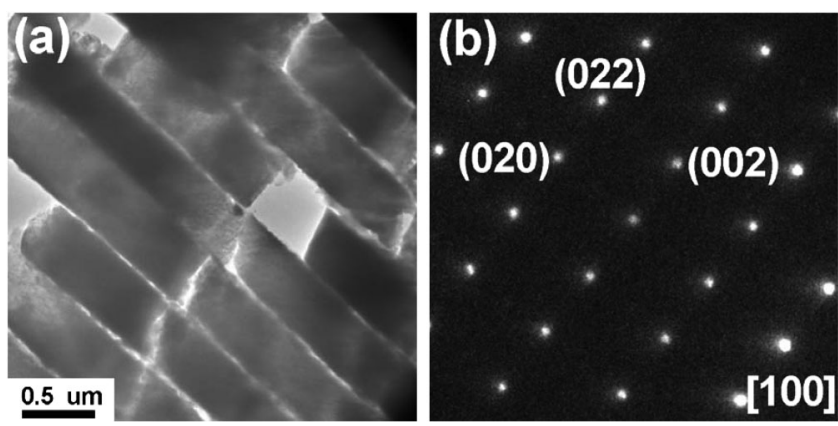

FIG. 1. Structural characterization of nacre. (a) TEM image of nacre's cross section, showing a brick wall-like architecture with aragonite platelets sandwiched with organic biopolymer interlayers. (b) Electron diffraction pattern of aragonite platelets, exhibiting single-crystal diffraction characteristics. 

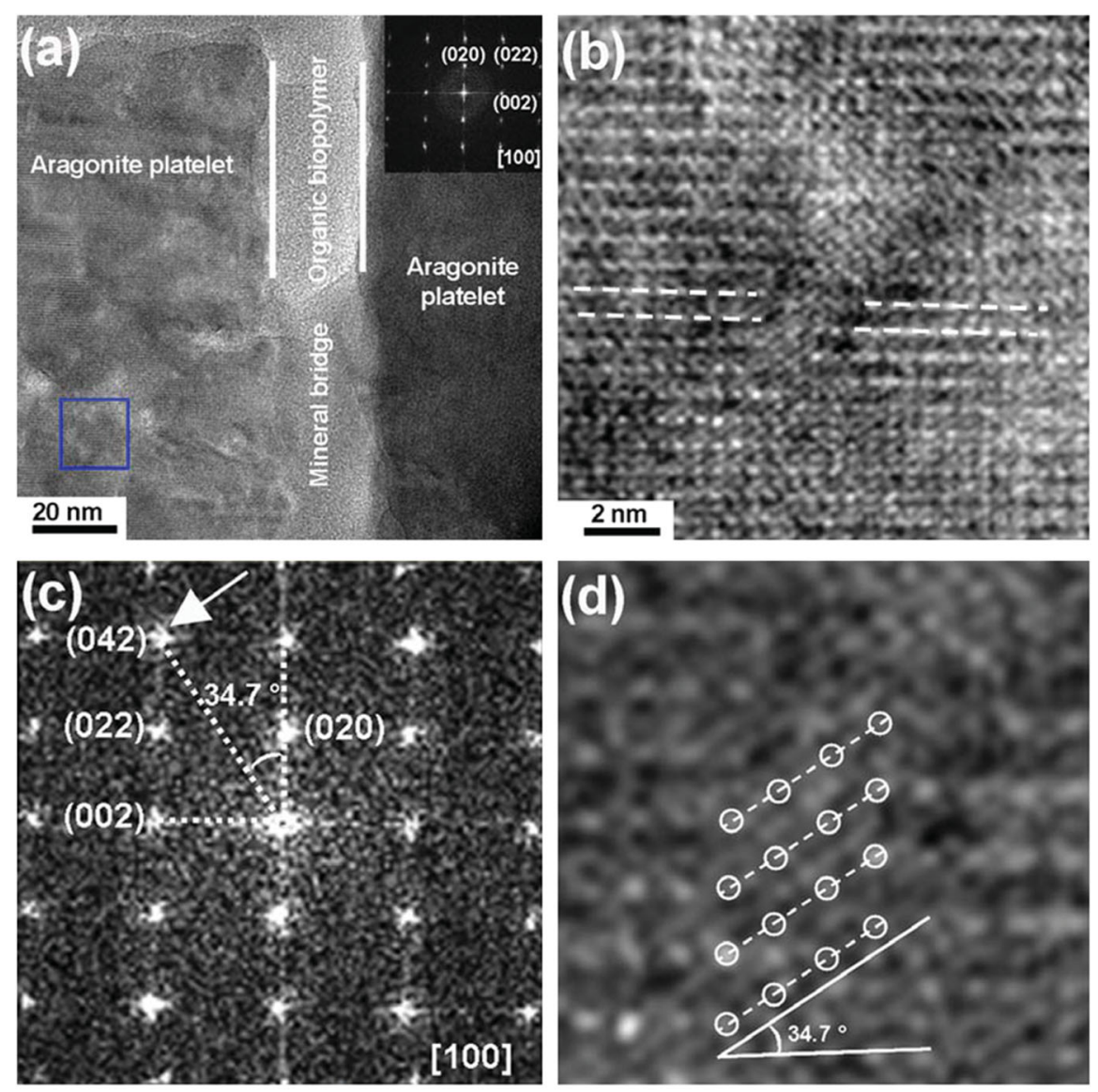

FIG. 2 (color). Observation and analysis of screw dislocation. (a) TEM image of two aragonite platelets with an organic biopolymer interlayer and a mineral bridge. (b) HRTEM image of the boxed area in Fig. 2(a), showing a screw dislocation lining two adjacent particles. (c) FFT pattern of the image in Fig. 2(b). (d) Close-up view of the atomic arrangement of the interface between the two adjacent nanoparticles. (e) Schematic showing that crystallographic planes linking the two adjacent nanoparticles are determined to be aragonite (042) planes. (f) Screw dislocation is visualized by considering slipping across the two adjacent nanoparticles by one and a half of lattice vector $\frac{3}{2}[010]$.
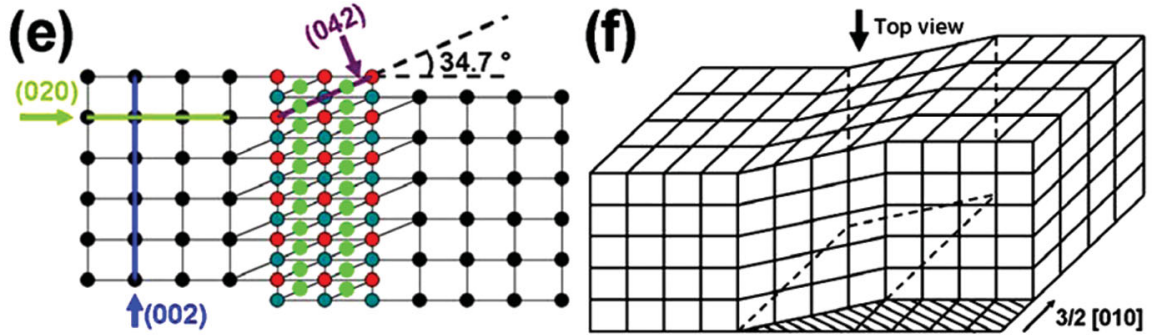

direction. Atomic arrangement at the interface is crystallographically different from that of the two adjacent particles, but the interface atoms are still packed in an ordered and repeated manner. The crystallographic planes linking the two adjacent nanoparticles were determined to be aragonite (042) planes [Figs. 2(b)-2(d)], which are schematically illustrated in Fig. 2(e). Such a type of crystallographic defect can be visualized as a screw dislocation, numerically corresponding to slipping across the two adjacent nanoparticles by one and a half of lattice vector $\frac{3}{2}$ [010]. Figure 2(f) is a three-dimensional schematic illustration showing how the two adjacent aragonite nanoparticles are assembled via such screw dislocation in a parallel manner.

Why does nature assemble aragonite nanoparticles through such a screw dislocation mechanism? Indeed, several independent studies reported screw dislocationbased spiral growth of aragonite platelets [9-13]. However, the assembly mechanism of the aragonite nano- particles inside individual platelets is completely unknown. The aragonite nanoparticles are defect-free crystals with unsatisfied surface bonds exposed to the mineral-solution or the mineral-organic interface during the biomineralization process. Thermodynamically, the assembly of aragonite nanoparticles is preferentially driven via reducing overall surface energy associated with the surface unsatisfied bonds. This requires that aragonite nanoparticles be oriented and attached to other nanoparticles or nanoparticle clusters. Such imperfect coherence between nanoparticles is realized in nacre by low energy driven screw dislocation. A similar assembly strategy was also demonstrated in a nanocrystalline titania particle system [14].

It was also found that in a single aragonite platelet, some nanoparticles do not hold the same crystal orientation, but why does the platelet exhibit single-crystal diffraction characteristics? Figure 3 shows the HRTEM images and corresponding FFT patterns of the nanoparticles in an 
aragonite platelet. The FFT pattern [inset in Fig. 3(a)] from the whole image of Fig. 3(a) clearly exhibits single-crystal diffraction characteristics. Figure 3(a) contains at least three nanoparticles, as indicated by boxed areas b, c, and $d$ in the figure. The FFT patterns of these three boxed areas reveal that particles $b$, c, and $d$ have different crystal orientations. The diffraction patterns of particles b, c, and d can be indexed [100], [11̄0], and [22̄1] zones, respectively. When the three diffraction patterns are superposed [Figs. 3: $\left(\mathrm{b}^{\prime \prime}\right)+\left(\mathrm{c}^{\prime \prime}\right)+\left(\mathrm{d}^{\prime \prime}\right)$ ], surprisingly, they form a single-crystal-like diffraction pattern [Fig. 3(a")], i.e., pseudo-single-crystal effect. The unique crystal structure of aragonite and the arrangement of the aragonite nanoparticles in nacre's platelets make the diffraction patterns of individual platelets show single-crystal characteristics, which have confused us for decades.
Geometrically speaking, it is impossible that all aragonite nanoparticles are assembled by screw dislocation to achieve a high packing density. What is the other mechanism that works together with screw dislocation to assemble aragonite nanoparticles into individual platelets? We found amorphous phase between some aragonite nanoparticles, as shown in boxed area $e$ in Fig. 3(a). This suggests that amorphous aggregation is another mediating mechanism between nacre's aragonite nanoparticles during the biomineralization process. The amorphous layer between nanoparticles would assist the particles' rotation and hold the surrounding nanoparticle clusters to share a specific crystallographic orientation. Figure 4 shows such an aragonite nanoparticle being assembled (docked) to the assembled aragonite platelet. It is believed that screw dislocation and organic biopolymer
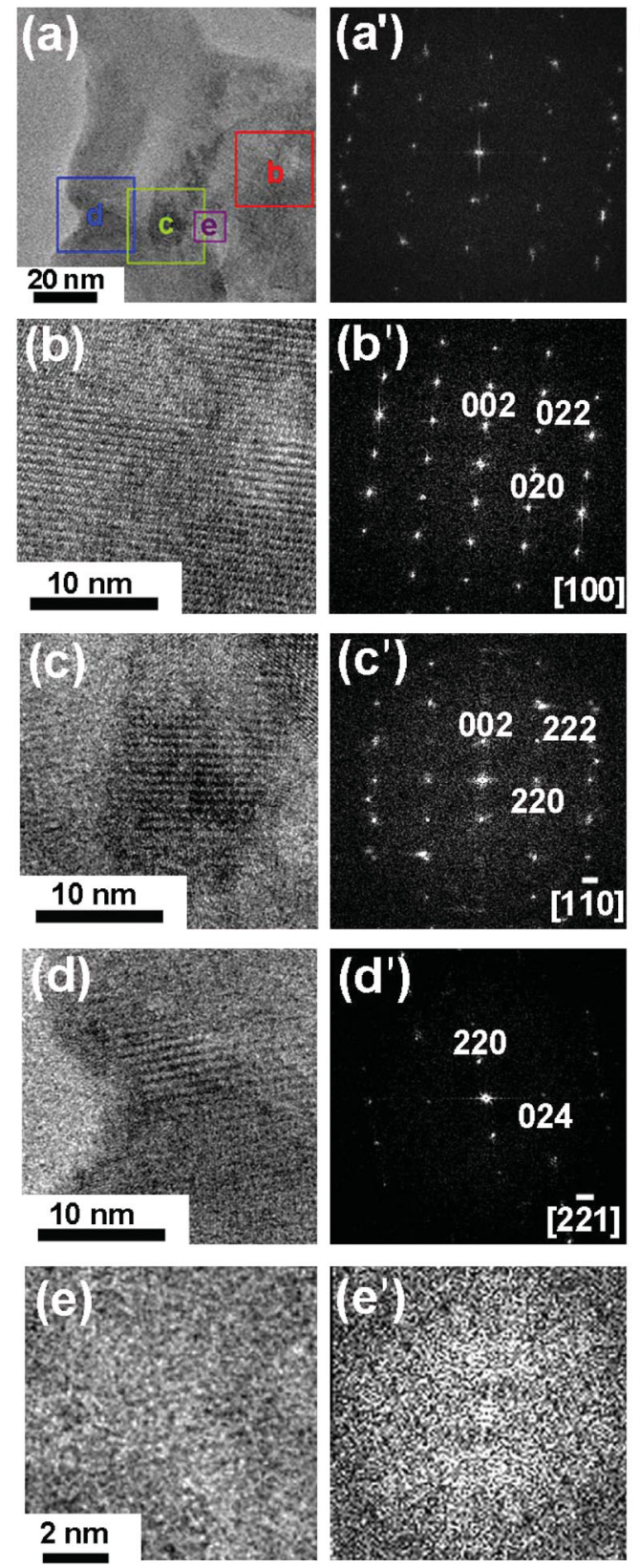
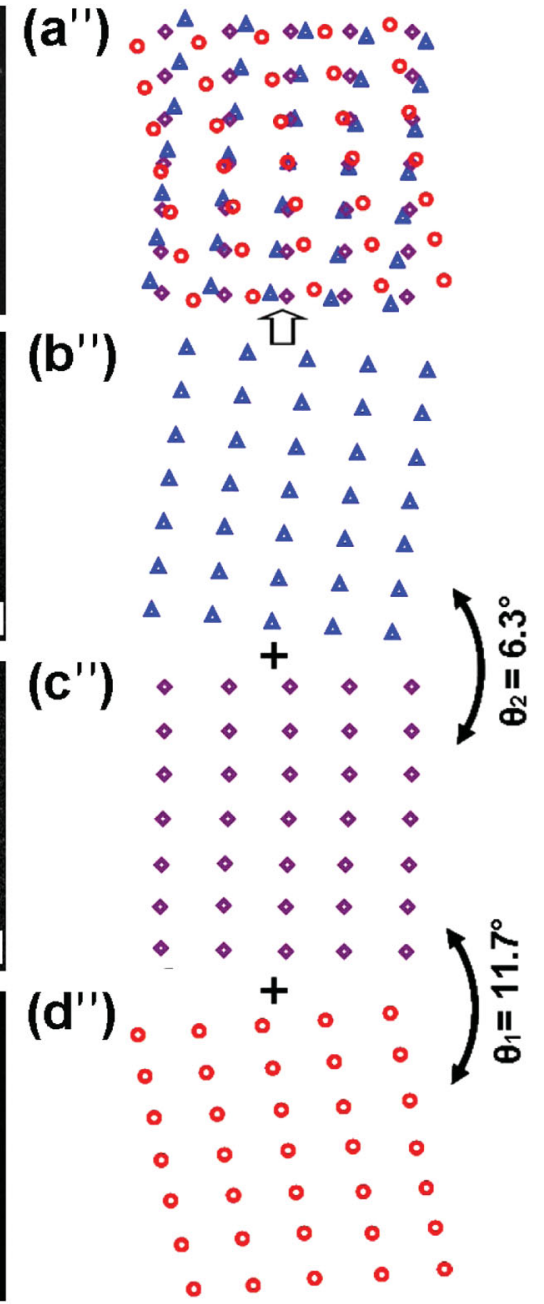

FIG. 3 (color). Pseudosingle crystal effect. (a) HRTEM image of an aragonite platelet. (b)-(e) Close-up views of boxed areas b, c, d, and e in (a). $\left(\mathrm{a}^{\prime}\right)-\left(\mathrm{e}^{\prime}\right)$ Respective FFT patterns of (a)-(e). $\left(a^{\prime \prime}\right)-\left(d^{\prime \prime}\right)$ Schematics of FFT patterns from corresponding images showing $\left(\mathrm{b}^{\prime \prime}\right)+\left(\mathrm{c}^{\prime \prime}\right)+\left(\mathrm{d}^{\prime \prime}\right)=\left(\mathrm{a}^{\prime \prime}\right)$. 

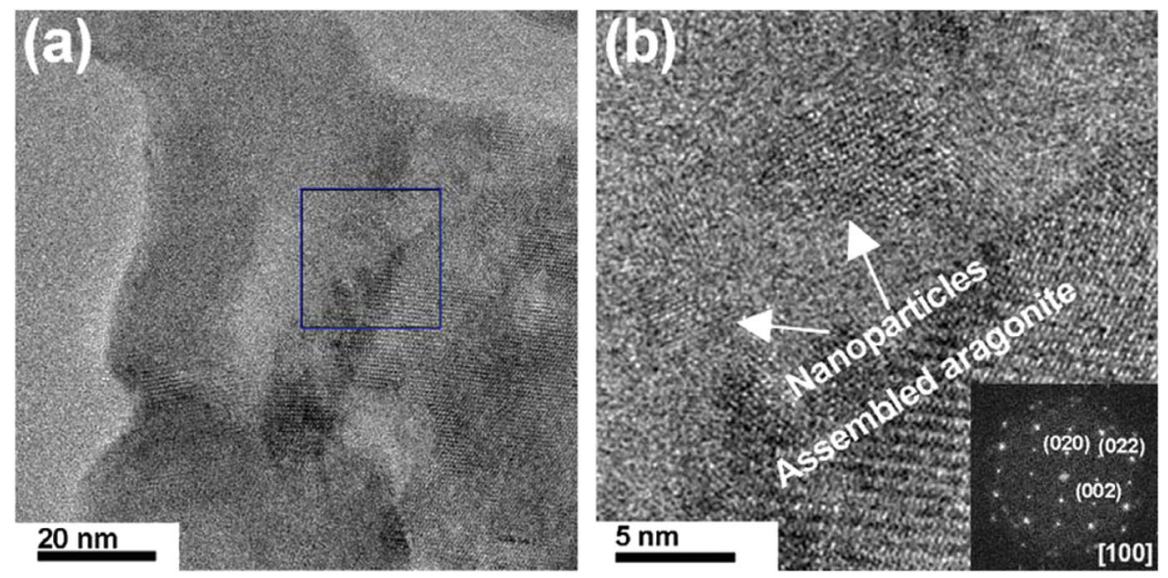

FIG. 4 (color). Nanoparticle assembly characteristics. (a) HRTEM image of an aragonite platelet. (b) Close-up view of two nanoparticles attached to the assembled aragonite platelet.

aggregation work together in assembling aragonite nanoparticle into individual platelets.

In summary, we have demonstrated direct evidence that a single-crystal-like aragonite platelet is essentially assembled with aragonite nanoparticles. Screw dislocation and amorphous aggregation are two dominant mediating mechanisms between nanoparticles during nacre's biomineralization process. The unique crystal structure of aragonite and the arrangement of the aragonite nanoparticles in nacre's platelets make the diffraction patterns of individual platelets exhibit single-crystal characteristics.

This work was supported by the U.S. Army Research Office under agreement/grant No. W911 NF-07-1-0449. We thank R.Z. Wang for providing the nacre samples.

*Corresponding author. lixiao@engr.sc.edu http://www.me.sc.edu/research/nano/

[1] B. Mohanty, K. S. Katti, D. R. Katti, and D. Verma, J. Mater. Res. 21, 2045 (2006).

[2] A. P. Jackson, J. F. V. Vincent, and R. M. Turner, Proc. R. Soc. B 234, 415 (1988).
[3] X.D. Li, W.C. Chang, Y.J. Chao, R.Z. Wang, and M. Chang, Nano Lett. 4, 613 (2004).

[4] Q.L. Feng, F.Z. Cui, G. Pu, R.Z. Wang, and H. D. Li, Mater. Sci. Eng., C 11, 19 (2000).

[5] N. Nassif, N. Pinna, N. Gehrke, M. Antonietti, C. Jager, and H. Colfen, Proc. Natl. Acad. Sci. U.S.A. 102, 12653 (2005).

[6] F. Barthelat, C. M. Li, C. Comi, and H.D. Espinosa, J. Mater. Res. 21, 1977 (2006).

[7] M. Rousseaua, E. Lopeza, P. Stempfle, M. Brendle, L. Franked, A. Guetted, R. Naslaind, and X. Bourrat, Biomaterials 26, 6254 (2005).

[8] X.D. Li, Z.H. Xu, and R.Z. Wang, Nano Lett. 6, 2301 (2006).

[9] K. Wada, Nature (London) 211, 1427 (1966).

[10] M. Fritz, A. M. Belcher, M. Radmacher, D. A. Walters, P. K. Hansma, G. D. Stucky, D. E. Morse, and S. Mann, Nature (London) 371, 49 (1994).

[11] S. Blank, M. Arnoldi, S. Khoshnavaz, L. Treccani, M. Kuntz, K. Mann, G. Grathwohl, and M. Fritz, J. Microsc. 212, 280 (2003).

[12] N. Yao, A. Epstein, and A. Akey, J. Mater. Res. 21, 1939 (2006).

[13] K. Tushtev, M. Murck, and G. Grathwohl, Mater. Sci. Eng., C (to be published).

[14] R. L. Penn and J. F. Banfield, Science 281, 969 (1998). 